\title{
Un teatro para la nueva población urbana: los resortes de la cultura masiva en La viuda valenciana de Lope de Vega
}

\author{
Jaume PERIS BLANES \\ Departamento Filología Española, Universitat de València \\ Jaume.peris@uv.es
}

\begin{abstract}
RESUMEN
El artículo analiza el texto de La viuda valenciana, de Lope de Vega, en el contexto de la redefinición de la función del espectáculo a finales del siglo XVI y principios del XVII. Se centra en la relación entre las características de la nueva población urbana de la sociedad barroca y la emergencia de una cultura masiva de la que el teatro constituye una pieza fundamental y que, entre otras funciones, cumple el rol de dar sentido e integrar en tramas coherentes a algunas de las preocupaciones y miedos fundamentales de esa nueva población urbana, como la creciente movilidad social, la maleabilidad de los roles de género o la sensación de desorientación subjetiva.
\end{abstract}

Palabras clave: La viuda valenciana, Lope de Vega, cultura masiva, enredo, género, población urbana.

\begin{abstract}
The article analyzes The valencian widow (Lope de Vega) in the context of changing conceptions of spectacle at the end of XVIth century and the beginning of XVIIth. The author focus on the relationship between main features of new urban population and the emergency of mass culture dynamics. Theatre played a key role in that emergent mass culture, giving sense and including in coherent plots some preoccupations and fears of that urban population, such as social mobility, ambiguity of gender roles or subjective disorientation.
\end{abstract}

Keywords: The Valencian Widow, Lope de Vega, mass culture, gender, urban population.

Sumario: 1. Teatro y sociedad en el barroco: los resortes de una cultura masiva. 2. Del enredo y el engaño como metáforas de la desorientación social. 3. Masculino / Femenino: el problema de los géneros. 4. Del amor trasgresor al orden matrimonial. 5. Conclusiones

A finales del siglo XVI y principios del XVII el teatro español se consolidó como una forma de espectáculo, de negocio empresarial y de producción literaria que anunciaba el funcionamiento de lo que mucho más adelante se conocería como la cultura masiva. La concepción teatral de Lope de Vega contribuyó decisivamente 
a ello en dos aspectos fundamentales: en primer lugar, su relación con mecenas, compañías y público abrió el camino para una incipiente profesionalización del escritor dramático; en segundo lugar, que es el que interesa en estas páginas, su concepción del espectáculo y la escritura dramática le llevó a situar el gusto del público como eje principal de la composición y, por tanto, a tratar en las tramas aspectos de la realidad social de su público que permitieran conectar directamente con la sensibilidad popular.

El objetivo de este artículo es analizar el modo en que su singular obra La viuda valenciana hace suyas algunas de las preocupaciones fundamentales de la nueva población urbana a la que iba dirigida y les da una forma dramática muy eficaz. Para ello, en la primera parte, se planteará la relación entre las características de la nueva población urbana de finales del XVI y la emergencia de nuevas formas del ocio que culminarán con la consolidación de una nueva cultura de orientación masiva. En la segunda parte, se verá cómo el enredo, el engaño y la equivocidad dispositivos básicos en la configuración de la comedia urbana- funcionan, en $L a$ viuda valenciana, como metáforas de la desorientación social de la nueva población urbana y aluden indirectamente a algunas de sus preocupaciones mayores. En la tercera parte, el análisis se detendrá en el modo en que la obra de Lope plantea el conflictivo problema de los roles de género en la nueva sociedad urbana, tematizando insistentemente su ambigüedad, maleabilidad y equivocidad. En la cuarta parte, se revisará el modo en que el deseo, fuente del catálogo de transgresiones que la obra presenta, es reconducido al final a un contrato matrimonial que pareciera anular su carácter disruptor. En el capítulo final se vinculará esa evolución en la concepción del amor con la presencia del problema estamental en la obra.

\section{Teatro y sociedad en el barroco: los resortes de una cultura masiva}

En sus estudios ya clásicos sobre el teatro en la sociedad barroca, José Antonio Maravall presentó la tesis de que el teatro áureo cumplía una función eminentemente propagandística: el teatro consistiría en un instrumento popularmente eficaz para socializar un sistema de convenciones sobre las cuales se sostenía el orden social que las clases poderosas necesitaban conservar (1990: 20). Esa vinculación tan directa entre el poder político y el teatro, que convertía a éste último en una fenomenal herramienta persuasiva y en un instrumento explícito del orden monárquico-señorial, ha sido matizada y contestada en fechas posteriores por diferentes trabajos que, implícita o explícitamente (Oleza, 1994; Connor Swietliki 1998), cuestionaban esa homogeneidad de las prácticas teatrales barrocas y su subordinación generalizada con respecto a los intereses de los grupos e ideologías dominantes.

Efectivamente, como se tratará en este trabajo, la representación de las relaciones sociales y humanas que tiene lugar en el teatro barroco no puede reducirse a una mera actividad de propaganda, si entendemos ésta como una forma 
consciente, dirigida y organizada de persuasión destinada a producir un fin político concreto - la aceptación de una serie de convenciones y la consolidación de un modelo social-, bien definido y que determinaría la producción del texto dramático y sus estrategias de representación. Aunque algo de ese propósito hubiera en la obra de algunos autores, lo cierto es que buena parte de la creatividad del teatro barroco escaparía a ese esquema de interpretación.

Sin embargo, los propios trabajos de Maravall, (1983 y 1990) aportan una clave para pensar de otro modo el mismo problema: definen la cultura del barroco como la primera que opera con los resortes de una cultura masiva y, por tanto, como una cultura que se dirige a un público que, por primera vez, reúne los atributos del moderno público masivo. Si bien los conceptos de 'masa' y de 'lo masivo' son evidentemente muy posteriores a la cultura barroca, y su uso pudiera parecer anacrónico, lo cierto es que el teatro que ve la luz a finales del XVI y se consolida como práctica espectacular durante todo el siglo XVII participa de esa concepción moderna, creando los pilares de lo que en siglos posteriores derivará en la cultura masiva contemporánea.

Aspectos como la profesionalización de autores y compañías, la autonomización de los espacios de representación o la estandarización de los repertorios y los géneros dramáticos constituyen procesos fundamentales para la aparición de esta emergente cultura masiva, que han sido estudiados por la crítica reciente. Pero además, y esto es lo que interesa en estas páginas, el teatro barroco llevó a cabo una función social primordial consistente en organizar narrativa y espectacularmente algunos conflictos sociales y dotarlos de un orden y un sentido del que probablemente carecían en la realidad. Ese proceso de organización narrativa es el que Maravall, dada su tendencia mayoritariamente conservadora, leía bajo el prisma de la propaganda, quizás obviando su heterogeneidad y las muy diversas opciones y representaciones de la sociedad que hubo en su seno.

Para comprender la emergencia de esa nueva cultura masiva debemos recordar algunos de los aspectos esenciales de la sociedad en la que tiene lugar el teatro barroco. Se trata de una sociedad en crisis y bajo los efectos del shock producido por el paso de la sociedad medieval a la moderna, es decir, por el paso de una sociedad tradicional en la que a cada persona correspondía una función social definida, natural e inamovible a una sociedad más abierta, a partir del siglo XVI, todavía estratificada pero con mayores posibilidades de movilidad social. Además, ese proceso se vio acompañado por un importante éxodo rural y una creciente concentración urbana durante los siglos XV y XVI, que generó la aparición de una nueva población urbana, fundamental para la emergencia del teatro barroco, ya que iba a constituir una parte sustancial de su público. Se trataba de de un nuevo grupo poblacional, heterogéneo y carente de arraigos, marcado por el shock de un cambio acelerado en su forma de vida y por la brusca mutación de los códigos sociales por los que se regían la antigua vida rural y la nueva vida urbana. 
No es extraño, en ese contexto, que la profunda redefinición de los espacios y de las prácticas urbanas que tuvo lugar durante el siglo XVI se acompañara de nuevas figuras subjetivas marcadas por la desorientación, la incapacidad para descifrar y hacer suyos los nuevos códigos morales y por el asombro -maravillado o aterrorizado- ante las nuevas formas de sociabilidad y las nuevas figuras de la subjetividad. Es lo que Marshall Berman describió como una "experiencia a tientas de la modernidad" (1988: 3), una primera fase de la modernidad que se abriría con las grandes transformaciones del siglo XVI y que se hallaba ligada a la reformulación de la vida urbana y del tiempo vital de las personas en ella. Individuos que habían nacido y crecido en comunidades regidas por la autoridad de la tradición y cuyo lugar en ellas estaba perfectamente definido, debían enfrentarse a una configuración social en formación y con códigos, valores y roles en continua transformación.

En ese contexto, el espectáculo teatral barroco abasteció a esa nueva población de las ciudades de una nueva forma de entretenimiento acorde con los ritmos de la vida urbana. Les ofreció, además, relatos en los que reconocer algunas de sus experiencias, proyectar sus sueños de ascenso y consolidación social y vehicular sus miedos y angustias ante la emergencia de nuevos códigos e identidades. Se trató, de hecho, de una práctica cultural incluyente, ya que asistir a las funciones se convertiría, en buena medida, en una forma de pertenecer a una comunidad imaginaria que compartía unas experiencias similares, que se mostraba preocupada por problemas comunes y que, además, consumía los mismos relatos y podía referirse a ellos para explicar algunas de las claves de su propia sociedad. Son estos los rasgos propios de una concepción masiva de la cultura, de aspiración interclasista, incluyente y que absorbe las preocupaciones centrales de su público para darles un sentido narrativo convincente y para resolver sus conflictos de un modo apaciguador.

El Arte nuevo de hacer comedias en este tiempo (1609) de Lope de Vega supone, en ese contexto, el intento de gramaticalizar una forma de composición teatral acorde con la nueva concepción del teatro como espectáculo masivo. Como texto preceptivo supone una revolución en la argumentación teórica, dado que deriva todas sus consideraciones técnicas (la crítica de las unidades, la mezcla de lo cómico y lo serio, el uso de la polimetría...) de un cambio fundamental en la concepción del teatro: la autoridad no puede ser más la preceptiva clásica ("cuando he de escribir una comedia / encierro los preceptos con seis llaves" vv. 40-41) sino un concepto novedoso en la teoría poética, que vendrá a reordenar todos los procesos de construcción dramática: el gusto del público y la voluntad de lograr el aplauso de los hombres vulgares ("escribo por el arte que inventaron / los que el vulgar aplauso pretendieron" vv. 45-46). La explicación de ese cambio de perspectiva es nítida y sencilla: la dependencia de los nuevos conceptos teatrales de la mercantilización del arte teatral, y de su vinculación a un circuito económico del 
que el público vulgar constituye un nuevo y diferente mecenas ("porque, como las paga el vulgo, es justo / hablarle en necio para darle gusto" vv. 46-47).

Con su discurso sobre el Arte nuevo, Lope no hacía sino teorizar sobre una concepción de la comedia y del teatro que desde aproximadamente mediados del siglo pasado se había ido consolidando como una forma de ocio de primera importancia en las ciudades españolas. Su propia obra dramática a finales del XVI influenciado decisivamente por la escuela valenciana- consagró una forma de entender el teatro como espectáculo masivo y sentó las bases para la consolidación de una sintaxis teatral muy definida que su obra llevaría a la perfección y que autores contemporáneos y posteriores explorarían incesantemente durante todo el siglo XVII.

Esa sintaxis teatral incluía estructuras argumentales, usos de los personajes, técnicas de composición poética y de construcción escénica, pero todos esos elementos se hallaban subordinados a una operación esencial: hacer conectar las tramas con la sensibilidad de un público heterogéneo. Para ello, el nuevo teatro aludió y representó en sus tramas algunas de las frustraciones, aspiraciones, conflictos y problemáticas que atravesaban a la sociedad barroca y, especialmente, a la nueva población urbana. Lo hizo de formas muy diferentes, pero todas ellas tenían un elemento en común: crear tramas coherentes, entretenidas y eficaces en las que esos conflictos y aspiraciones adquirieran un sentido del que, probablemente, carecieran en la realidad. Esto es, traducir esos conflictos que angustiaban a la nueva sociedad a tramas coherentes que simplificaran e hicieran inteligibles problemas sociales de muy difícil solución.

Toda la obra dramática de Lope de Vega está atravesada por esa concepción del teatro como procesadora de conflictos sociales. En muchos aspectos, los dramas de honra, los que tematizan el abuso de poder de los señores o aquellos en los que el monarca intercede a favor de un villano honesto, constituyen ejemplos perfectos de cómo un problema socio-político de primer orden -el del conflicto de poder entre los antiguos señores feudales y la monarquía, y el difícil lugar de los villanos ricos entre ellos- se traduce a compactos argumentos que ofrecen un sentido definido, sencillo y claramente inteligible a ese problema. Maravall ha estudiado con profundidad los componentes ideológicos de esa traslación, así como el modo en que, por ejemplo, las comedias presentan, en sus tramas amorosas, el problema estamental. Volveremos sobre ello más adelante.

Pero además, muchas de estas comedias realizan una operación de representación que está más allá de esa función ideologizante, aunque se relacione directamente con ella. De un modo complejo y sutil, las comedias representan estados de ánimo, situaciones, posiciones afectivas y emotivas que esa nueva población urbana a la que he hecho referencia anteriormente no puede dejar de reconocer como propias. De ese modo, la comedia no sólo trata de conectar con la sensibilidad del público y de ganar su aplauso y su favor, sino que, además, trata de 
canalizar no pocas de sus angustias sociales, dándoles coherencia narrativa y representación dramática.

\section{Del enredo y el engaño como metáforas de la desorientación social}

Permítaseme, para ejemplificar la hipótesis anterior, analizar el modo en que una comedia urbana del primer Lope, La viuda valenciana, propone representaciones de algunos aspectos concretos de la subjetividad barroca. En especial, interesa el modo en que Lope utiliza la mecánica del enredo y el engaño de un modo creativo para situar a sus personajes en una dinámica de desorientación, que se resolverá finalmente de un modo positivo, pero que en el discurrir de la trama somete al protagonista principal a una situación de indefensión y de incapacitación perceptiva.

Recordemos brevemente la apertura de su trama argumental: Leonarda ha enviudado recientemente y es dueña de una importante fortuna, además de mostrarse notablemente atractiva a los ojos de todos los varones de la obra. Sin embargo, y en contra de las convenciones sociales y del consejo de su criada Julia y de su tío Lucencio, Leonarda descarta un nuevo casamiento, pues desea evitar las servidumbres del matrimonio. A pesar de ello, Leonarda se enamora de Camilo galán con el mismo nombre que su difunto marido-, lo cual no cuestiona su decisión de renunciar al matrimonio, sino que le obliga a urdir una compleja estrategia para atraer al galán a su casa y poder mantener relaciones amorosas con él. El galán acudirá a su casa, pero lo hará con los ojos tapados por una máscara, lo que le impedirá conocer la ubicación de la casa y ver el rostro de su amante, con quien mantendrá relaciones sexuales en la total oscuridad. Camilo no tardará en enamorarse, aun desconociendo la identidad y el aspecto físico de su amante, lo cual provocará que la trama evolucione hacia nuevas peripecias centradas en su incapacidad para reconocer a su amada.

De entrada, el enredo, el engaño y la ocultación constituyen los mecanismos constructivos fundamentales de la trama, en los que descansa todo su desarrollo. En su estudio sobre el uso del engaño, Roso Díaz señala una evolución en la producción lopesca, paralela a la evolución constructiva de sus tramas. En sus obras de madurez, en las que el modelo de la comedia estaría ya consolidado, podrían diferenciarse nítidamente dos usos: en primer lugar, un uso estructural del engaño, como motor que genera el enredo y como auténtico elemento vertebrador del ritmo de la comedia; en segundo lugar, un uso más episódico y secundario, extirpable de la acción, pues no es pertinente en ella más allá de la escena en que se da (1999: 119). Sin embargo, en las obras tempranas de Lope, esa diferenciación entre un uso estructural y episódico no es tan nítida, lo que se concreta en un número de engaños muy elevado y de carácter episódico, lo que dispersaría la acción y haría que los diferentes elementos de la trama presentaran una menor integración narrativa (1999: 120).

La viuda valenciana, de hecho, pertenece a ese grupo de obras tempranas que Joan Oleza denomina la primera manera del teatro de Lope, en la que predominan las comedias de diferentes géneros (urbanas, palatinas, picarescas, pastoriles, 
novelescas) y que está marcada por la experimentación sobre elementos de prácticas escénicas anteriores, una gran audacia moral y por una gran libertad tanto estética como ideológica. También por construcciones argumentales tentativas, que no han alcanzado todavía el rigor del perfecto mecanismo argumental que caracteriza a las obras de madurez (vide. Oleza 1997). Sin embargo, dentro de ese grupo La viuda valenciana es un texto tardío, compuesto probablemente a finales de 1599 o principios de 1600 (Ferrer Valls, 2001: 17-18) y en el que la audacia moral e ideológica de esa primera manera está vehiculada por una trama que apunta los rasgos de sus comedias de madurez.

También en el uso del enredo La viuda valenciana presenta esos rasgos de transición entre los dos modelos que diferencia Roso Díaz, y a los que se ha hecho referencia anteriormente. Hay un enredo fundamental que vertebra la acción -la ocultación de la identidad de Leonarda a su amante- y numerosos enredos episódicos, que tienen como protagonistas a los tres galanes que disputan la mano de Leonarda -Otón, Valerio y Lisandro- y a los criados de los personajes principales. Incluso, cuando Camilo cree tener las piezas necesarias para deshacer el enredo, dado que desenmascara al criado Urbán, Leonarda urde otro engaño, haciéndole creer que la mujer de quien se ha enamorado es su prima, mujer mayor y poco atractiva ${ }^{1}$. Pero si bien la articulación entre todos ellos pueda resultar poco rigurosa, lo cierto es que la obra apunta diferentes elementos que los dotan de homogeneidad, dándoles una cierta verosimilitud dramática y legitimando la sucesión de engaños, embustes y mascaradas que presenta la trama.

La ubicación de la trama en tiempos de carnaval constituye, sin duda, el principal recurso para articular y dotar de coherencia a las diferentes formas del enredo que presenta la obra, y especialmente el enredo principal:

$\begin{array}{ll}\text { LEONARDA: } & \text { Ya ves cómo anda alterada } \\ & \text { Con sus máscaras Valencia } \\ \text { URBÁN: } & \text { Bien. } \\ \text { LEONARDA: } & \text { Pues con esta licencia } \\ & \text { Ponte una ropa estremada, } \\ & \text { Y unas máscara, y camina } \\ & \text { A hablar aquese galán, } \\ & \text { Y dile en disfraz, Urbán, } \\ & \text { Que una dama se le inclina, } \\ & \text { Y que le ama tiernamente } \\ & \text { Y que la podrá gozar }\end{array}$

${ }^{1}$ Las palabras 'engaño' y 'desengaño' aparecen recurrentemente en la obra y especialmente en boca del personaje que mueve los hilos: "A su posada / Ve esta noche; que me agrada / Con otro mayor engaño / Dalle un cierto desengaño" (vv. 2731-2734). 


$\begin{array}{ll} & \text { Como hoy te quiera esperar } \\ & \text { Del Real dentro en la puente. } \\ & \text { Y si te dice que sí, } \\ & \text { Esta noche irás por él. } \\ \text { LRBAN: } & \text { Luego ¿bien ha de ver él } \\ \text { LEONARDA: } \quad \text { No, que con máscara irás, } & \text { Y para que nada note, } \\ & \text { Le pondrás un capirote, } \\ & \text { Con que a casa le traerás. } \\ & \text { Entrará a escuras, y cuando } \\ & \text { Se haya de ir, vuelto a poner } \\ & \text { ¿a quién podrá conocer? (vv. 771- 793). }\end{array}$

En sus estudios sobre la cultura popular, Mijail Bajtin señaló la importancia de la fiesta carnavalesca en la Edad Media y el Renacimiento, ya que suponía un periodo de suspensión de las normas y las reglas sociales, opuesto al de las fiestas oficiales que servían para consolidar las relaciones de poder y el orden social existente. Sin embargo, a diferencia de la fiesta oficial, el carnaval constituía "el triunfo de una especie de liberación transitoria, más allá de la órbita de la concepción dominante, la abolición provisional de todas las relaciones jerárquicas, privilegios, reglas y tabúes" (1998: 15).

En el siglo XVII el carnaval comenzó a perder la fuerza disruptiva de épocas anteriores pero en el imaginario colectivo se seguía asociando no solamente a un tiempo de ruptura con lo establecido, transgresión moral y permisividad de las autoridades, sino también a un periodo en el que era posible reinventarse a sí mismo y hacerse pasar por lo que, fuera de ese periodo, no se era. En La viuda valenciana, de hecho, no se pone el acento en la potencia de disrupción social del carnaval, sino en que su equivocidad moral es instrumentalizada por Leonarda para sacar provecho personal, amparándose en la suspensión de la identidad que el carnaval posibilita: como momento en el que las identidades individuales se ocultan, constituye un periodo privilegiado no sólo para el enredo, sino también para el mantenimiento de la honra, entendida de acuerdo a los principios barrocos.

El carnaval es, pues, el espacio-tiempo en el que se sitúa la acción. El hecho de que en algunas reposiciones de la obra se cambiara su título original por el de Las máscaras valencianas (Ferrer Valls 2004: 472) indica hasta qué punto la cuestión del carnaval resultaba relevante para el sentido que se daba a la trama. Por una parte, constituye la condición de posibilidad para el engaño principal sobre el que se sostiene la obra, como se ha visto en el anterior fragmento. Por otra, al poblar la escena de disfraces y enmascarados, verosimiliza otros enredos episódicos: en una escena muy cómica, los galanes secundarios Otón y Valerio entran a casa de Leonarda disfrazados respectivamente de librero francés y de estampero y aprovechan para hacerle requiebros y tratar de seducirla. Su habilidad es tan poca 
que Leonarda no tarda en descubrir el engaño, pero esa peripecia contribuye a reforzar el clima de enredos, identidades fingidas, ocultamientos y falsas realidades en el que se desarrolla la trama.

Ese es, de hecho, uno de los aspectos centrales de la comedia urbana del barroco, que La viuda valenciana lleva al extremo: la abundancia de situaciones en las que los personajes actúan engañados, sometidos a una falsa percepción de la realidad y a una lógica de los acontecimientos que no alcanzan a comprender. Si bien hay un personaje -Leonarda- que, controla la situación, urde el engaño y mueve los hilos de la trama, el otro personaje principal, Camilo, experimenta durante toda la trama una sensación de desorientación que irá en aumento a medida que se desarrolla el enredo. Muchos de los parlamentos de Camilo inciden en esa idea y en los efectos subjetivos de andar por la ciudad con los ojos cubiertos ("No hay qué repare / Más que en el ir tan cubierto" (vv. 976-977) y gozar de su amada en la completa oscuridad (“¿Qué importa que bella sea / Si a escuras he de gozalla?” (vv. 971-972). Esa peripecia el propio personaje la presenta como una situación de desamparo, en la que, ingenuamente, se pone a merced de la locura de alguien a quien desconoce.

$\begin{array}{ll}\text { CAMILO: } & \text { ¿Qué cubierto tengo de ir? } \\ \text { URBÁN: } & \text { Y desa suerte, Camilo, } \\ & \text { Habéis de entrar y salir. } \\ \text { ¿Buen ánimo, pensamiento, } & \text { De temeridad vestido! } \\ & \text { Al puesto habemos venido } \\ & \text { Donde vuestro atrevimiento } \\ & \text { Me lleva a vencer vencido. } \\ & \text { Entre el temor y el deseo, } \\ & \text { Con quien batallo y peleo, } \\ & \text { Tantas veces quedo y voy, } \\ & \text { Que con estar donde estoy, } \\ & \text { Otras tantas no lo creo. } \\ & \text { ¿Qué se yo si algún contrario, } \\ & \text { De invidia de verme noble, } \\ & \text { Me forja este trato doble, } \\ & \text { Donde sea necesario } \\ & \text { El sufrir espada o roble? } \\ & \text { (..) Pero aunque vaya cual voy, } \\ & \text { ¿de qué peligro me escapa, } \\ \text { Si al fin los ojos me tapa? } & \text { Que pues sin ojos estoy, } \\ & \text { Bien puede echarme la capa. } \\ \text { ¿Quién oyó jamás tal cosa } & \text { Que una mujer hermosa, } \\ \text { Que tanto a un hombre desea, } & \text { no permita que la vea? }\end{array}$


¡Qué fama tan vergonzosa!

Y ¿qué sé yo si pensando

Que abrazo algún ángel bello,

A un demonio enlazo el cuello

Que ascuras anda volando

Porque es indigno de vello?

$¿ \mathrm{O}$ que fuese alguna vieja,

Ya sin pestaña ni ceja,

Con unos dientes postizos,

Que me hiciese con hechizos

Andar como simple oveja?

$¿ \mathrm{O}$ fuese alguna cuitada

Herida de mal francés,

Que me hiciese andar después,

Por un hora de posada,

Muerto dos años o tres? (vv. 1021-1075)

Dos elementos se ponen en juego en ese parlamento: en primer lugar, el miedo que produce la incapacitación perceptiva a Camilo, a quien deberá guiar el criado Urbán por toda la ciudad, sin que el galán pueda defenderse de potenciales peligros; en segundo lugar, y derivado del primero, la imposibilidad de distinguir la identidad fingida de la verdadera, la incapacidad hermenéutica para discriminar la mentira de la verdad y la dificultad de discernir entre un amplio repertorio de tipos urbanos cargados de peligros, misterios o placeres. Esa es la situación que la comedia de Lope genera y explora: un personaje incapacitado para interpretar adecuadamente los signos de la vida urbana y angustiado por la posibilidad de perderse entre ellos: Camilo señala en aparte irónico a Otón "Yo vengo muy bien armado / Sin ojos, como gallina" (vv. 1169-1170)².

2 La comedia presenta toda una serie de reflexiones sobre el deseo, el amor y su contradictoria relación con el sentido de la vista, ya que una de las particularidades de la trama es que Camilo se enamora de Leonarda sin haberla visto, aunque haya mantenido relaciones sexuales con ella a oscuras y haya quedado prendado de su cuerpo. En un primer momento, Camilo señala a Urbán: “¿Qué importa que bella sea, / Si a escuras he de gozalla? / Antes presumo que es fea" a lo que éste responde "En hablalla y en tocalla / Habrá luz con que se vea" (vv. 971-975). Más adelante en la trama, sigue dudando Camilo sobre la validez de los demás sentidos para una percepción adecuada, privilegiando el placer visual como una facultad específicamente humana, de acuerdo a la concepción neoplatónica del amor: “¿Soy herbolario o doctor? / ¿qué me importan a mí olores? / Los ojos hacen gozar; Que aquel ver causa el hallar / Suavidad en los amores, /Y el conocer y el tratar./ Que por el contrario, el ciego, / Como yo a esa dama llego, / Es en el deleite igual /A cualquier bruto animal" (vv. 1100-1109). Cuando, tras un nuevo engaño, Camilo cree que su amada es la vieja prima de Leonarda, atribuye su incapacidad para discriminar la juventud de la vejez a 
En el contexto del teatro barroco abundan este tipo de situaciones dramáticas, aunque quizás en la mayoría de las comedias carezcan de la nitidez que posee en $L a$ viuda valenciana, que prácticamente lleva a la abstracción la mecánica del enredo, urdiendo una trama que verosimilice el acto de vendarle los ojos a Camilo y hacerle recorrer la ciudad y gozar de su amante a ciegas. Esa situación, cuya comicidad explota hábilmente Lope, pone en el centro de la escena a un sujeto que experimenta la incapacidad para descifrar los signos, códigos y situaciones que pueblan la ciudad. Además, ese sujeto vive esa incapacitación de una forma ambivalente, que Marshall Berman describiría como típicamente moderna: a un tiempo goza y siente pánico ante una situación tan cargada de peligros como de placeres potenciales ${ }^{3}$.

la falta de visión: le espeta Floro, su criado “¿No me contabas tú que la tocaste, / Y que era moza muy briosa y cuerda, / Que hablaba con estremo y respondía?" a lo que responde Camilo "Sin ojos, no me culpes ni me corras" (vv. 2638-2642).

${ }^{3}$ Como muestra de esa ambivalencia moderna entre el miedo y el placer potencial ante una identidad de difícil definición, valga el siguiente fragmento, en el que Camilo expresa miedo ante la identidad mudable de Leonarda pero a la vez se siente atraído por el vértigo de la incertidumbre que ese misterio produce:

$\begin{array}{ll}\text { CAMILO: } & \text { Ella ¿es moza? } \\ \text { URBÁN: } & \text { No has de vella. } \\ \text { CAMILO: } & \text { ¿Casada, o doncella en duda? } \\ & \text { ¿Es viuda? } \\ \text { URBÁN: } & \text { Es tal que se muda } \\ & \text { En casada y en doncella, } \\ & \text { Y otras veces en viuda. } \\ & \text { Ni es viuda ni casada, ni violada } \\ & \text { De alguno que la desdeña } \\ \text { CAMILO: } & \text { Desa suerte, será dueña } \\ & \text { Entre algodones guardada. } \\ & \text { ¡Válate Dios por señora, } \\ & \text { Si te acabo de entender! } \\ & \text { (Engaño debe de haber. } \\ & \text { ¿Cosa que fuese éste agora } \\ & \text { Algún hombre y no mujer? } \\ & \text { (...) Mas gran deseo me inflama, } \\ & \text { Y este brío que hay en mí.) } \\ & \text { Amigo, vamos de aquí, } \\ & \text { A ver esa escura dama } \\ & \text { de aquellas que nunca vi. (vv. 1121-1145) }\end{array}$


Aquí llegamos a uno de los aspectos esenciales de la comedia barroca: la mecánica del enredo, los engaños, la abundancia de identidades fingidas difícilmente discernibles de las verdaderas, todo el juego de máscaras, ocultamientos y mentiras en que se sostienen sus tramas no sólo constituye una técnica para generar comicidad y diversión, sino que además traduce y dramatiza las sensaciones de desorientación, equivocidad y ausencia de puntos fijos que caracteriza a la experiencia de la nueva población urbana a la que antes se ha hecho referencia.

En ese sentido, una buena parte del éxito de la comedia barroca -y en este caso de la comedia urbana, que tiene al enredo como uno de sus mecanismos principalestiene que ver con su capacidad de procesar dramáticamente ese estado de desorientación y shock de la nueva población urbana, que había migrado de una sociedad tradicional en la que la posición del individuo estaba bien fijada desde su nacimiento, a ciudades marcadas por la velocidad de los cambios, la heterogeneidad de códigos y las posibilidades (más imaginarias que reales, pero con todo importantes) de movilidad social vertical. Para ese público, que sentía como propia la incapacidad de interpretar algunos de los nuevos códigos de la vida urbana, el mundo de engaños, identidades falsas y sujetos que andan a ciegas por la ciudad suponía una representación burlesca de ese espacio heterogéneo, repleto de sorpresas y de engaños que era la nueva ciudad barroca.

Por ello se puede afirmar que la mecánica del enredo da forma dramática a la equivocidad y volubilidad de los nuevos códigos urbanos, que hace de la identidad algo modelable y continuamente transferible; cifra, de ese modo, la angustiosa incapacitación hermenéutica de los nuevos sujetos urbanos. Las comedias dan, pues, una estructura narrativa y dramática eficaz al imaginario popular sobre la difícil inteligibilidad de las nuevas configuraciones sociales y sobre el desorden moral y sexual que habita en ellos. En el contexto de la sociedad barroca, por tanto, la comedia pone en escena y canaliza la sensación de desorientación ante los nuevos ritmos, identidades y dinámicas de la vida urbana. De ese modo, no sólo conecta con la sensibilidad de buena parte de sus espectadores y de la nueva población urbana: por una parte, contribuye a consolidar el imaginario de la decadencia, frivolidad e inmoralidad de las nuevas identidades urbanas; pero por otra, al integrar esos conflictos en estructuras dramáticas y narrativas coherentes, rebaja su poder angustiante al darle un sentido asumible por el público como verosímil.

\section{Masculino / Femenino: el problema de los géneros}

Como en muchas de las comedias barrocas, uno de los principales motivos de comicidad y uno de los principales elementos problemáticos de La viuda valenciana son las identidades de género: las actitudes de hombres y mujeres en tanto tales y la transgresión de las normas sociales que dictaminan los roles de género. La abundancia de situaciones en el teatro barroco en las que los roles socialmente 
asumidos para ambos sexos son cuestionados, vueltos del revés, problematizados y redefinidos ha sido interpretada de diversos modos por los historiadores del teatro. En este artículo interesa leerla en la perspectiva que abre una concepción del teatro como espectáculo masivo, orientado ideológicamente pero al mismo tiempo necesitado de conectar con la sensibilidad del nuevo público conformado por esa nueva población urbana de la que se ha tratado al principio.

Si bien, como se ha señalado, a la comedia pura -la urbana o de capa y espadase le encomendó, en el contexto general del teatro barroco, la dimensión lúdica del espectáculo (Oleza, 1994, 1997), no es menos cierto que su comicidad surge, en no pocos aspectos, de una lectura deformada de algunos de los elementos que, en el contexto de las nuevas sociedades urbanas, angustiaban y producían temor a la nueva población urbana. De hecho, la comedia lleva a su seno a la mayoría de elementos conflictivos que habían generado un shock masivo en las nuevas poblaciones urbanas: la multiplicidad de códigos de conducta, la posibilidad relativa de movilidad social, la anomia urbana, la opacidad de las relaciones sociales o, en fin, las nuevas formas de la subjetividad y, en relación a ello, las nuevas construcciones de género.

Sin duda la fijación de las identidades y roles de género constituía uno de los pilares fundamentales del orden tradicional y de su reproducción ideológica. En el contexto de los siglos XVI y XVII, de profundas transformaciones en la subjetividad urbana, la mutación de algunas conductas, representaciones y códigos de género -especialmente en el caso de las mujeres, pero también en el caso de los hombres- constituyó un motivo más de desasosiego y temor por parte de las nuevas poblaciones urbanas. El teatro barroco se hizo cargo de ello de un modo que será, a partir del siglo XVII, muy característico del operar de la cultura masiva: por una parte, hizo de la comedia un espacio para la escenificación liberadora de toda suerte de transgresiones y subversiones de la norma, muchas de las cuales tenían al deseo femenino y al erotismo como empuje principal; por otra parte, dio a esas gozosas transgresiones una clausura dramática conservadora y tradicional, que no invalidaba el potencial transgresor de las conductas anteriormente presentadas, pero que las despojaba de su potencial de desestructuración y disgregación social. En ese sentido, la comedia barroca supuso una respuesta cultural de primer orden, desde los presupuestos de una cultura masiva, a la creciente angustia social ante las nuevas configuraciones de género que empezaban a poblar la nueva sociedad urbana.

La viuda valenciana se abre con la constatación de un lugar específico para la mujer. Ferrer Valls $(2001,38-46)$ ha señalado cómo los primeros parlamentos de Leonarda expresan el punto de vista predominante en los tratados orientados a la educación de la mujer en la época. La propia Leonarda cita como autoridad la obra de Fray Luis de Granada, cuyo programa exhortaba al silencio, a la obediencia y a la reclusión de la mujer en el ámbito de la casa, y orientaba la lectura femenina hacia los libros sagrados y de devoción. Ante su nueva situación de viuda noble, 
rica y atractiva, que puebla de potenciales pretendientes su existencia diaria, Leonarda se reafirma en un principio en el rol que la tradición ha otorgado a su sexo. De ese modo, y ya desde sus primeras escenas, la comedia inscribe explícitamente en su trama el problema de los roles de género y su posible mutación:

LEONARDA: $\quad \begin{aligned} & \text { Basta una buena razón } \\ & \text { Y una honrada compostura, } \\ & \text { Julia, en cualquier mujer; } \\ & \text { Que si de aguda se precia } \\ & \text { Está muy cerca de necia } \\ & \text { Y aun de venirse a perder. } \\ & \text { Yo, después que me faltó } \\ & \text { Mi Camilo, que Dios tiene, } \\ & \text { Que a hacer el oficio viene } \\ & \text { Del alma que me llevó, } \\ & \text { Como he dado en no casarme, } \\ & \text { Leo por entretenerme, } \\ & \text { No por bachillera hacerme, } \\ & \text { Y de aguda graduarme. (vv. 19-32). }\end{aligned}$

La declaración de Leonarda alude a la relación subordinada de la mujer con respecto al saber en la sociedad barroca, y a su contradictoria relación con la cultura letrada y con el pensamiento racional. Pero lo hace de un modo irónico, ya que las propias palabras de Leonarda hacen pensar en una estrategia de ocultamiento de la inteligencia, con el fin de salvaguardar una imagen de acatamiento de la autoridad, en coherencia con el desarrollo posterior de la trama. En una comedia de plenitud como La dama boba, Lope llevaría esa problemática al centro del enredo en la figura de Nise, a quien la vivencia del amor transmuta de boba en inteligente y que se verá obligada a fingir una memez que, en los primeros compases del argumento, había sido bien cierta.

Sin embargo, La viuda valenciana alude también en sus primeras escenas, y por boca de su protagonista, a las nuevas figuras de la masculinidad que han aparecido en la nueva sociedad urbana del barroco. Esto es, la comedia no tematiza únicamente la codificación social del rol de la mujer, sino la cuestión del rol genérico en sí, ofreciendo no sólo un programa de feminidad para las mujeres -con todos los acatamientos, subordinaciones y composturas que ello implica-, sino también un modelo de masculinidad para los hombres. Como no podía ser de otra forma, esa reflexión proviene del rechazo visceral a las nuevas identidades de género, confusas, maleables y desplazadas, que comienzan a vislumbrarse en la modernidad urbana del barroco. Valga, para mostrarlo, la descripción, despectiva y exagerada, que Leonarda realiza de los nuevos hábitos de vestimenta masculina. 
LEONARDA: $\quad$ ¡No, sino venga un mancebo

Déstos de ahora, de alcorza,

Con el sombrerito de orza,

Pluma corta, cordón nuevo,

Cuello abierto muy parejo,

Puños a lo veneciano,

Lo de fuera limpio y sano,

Lo de dentro sucio y viejo!

¡botas justas, sin podillas

Descalzar en todo un mes,

Las calzas hasta los pies,

El bigote a las estrellas;

Jaboncillos y copete,

Cadena falsa que asombre,

Guantes de ámbar, y grande hombre

De un soneto y un billete;

$\mathrm{Y}$ con sus manos lavadas

Los tres mil de renta pesque

Con que un poco se refresque

Entre sábanas delgadas;

Y pasados ocho días

Se vaya a ver forasteras,

$\mathrm{O}$ en amistades primeras

Vuelva a deshacer las mías!

Vendrá tarde; yo estaré

Celosa; daré mi hacienda;

Comenzará la contienda

Desto de si fue o no fue.

Yo esconderé y él dará:

Buscará deudas por mí;

Entrará justicia aquí,

Voces y aun coces habrá.

No habrá noche, no habrá día,

Que la casa no alborote (...)

Y que mientras más me postro,

Me haga muy más apriesa

De dos títulos condesa,

Concentaina y Puñoenrostro.

Yo he dicho. (vv. 253-297).

Como puede verse, esa burlesca caracterización 'feminizada' de las nuevas masculinidades urbanas culmina con el temor a la violencia que esconde ese nuevo hombre tan preocupado por su estética y su parecer físico. Es, de hecho, el miedo a esa violencia y la nula atracción que le producen las nuevas figuras masculinas lo que inclina a Leonarda a permanecer en su estado de viudez, sin contraer 
matrimonio de nuevo. De forma irónica, frente a esa masculinidad feminizada, Leonarda describe su programa de independencia vital como el de una 'varonil mujer', que deberá renunciar a la pasión y a no pocos de los atributos considerados privativos de su género: "Esto propuse aquel día, / y a ser varonil mujer, / brasas había de comer / y abrasar alma tan fría" (vv. 301-304).

Esa insistencia en el carácter mudable de los atributos de género, que es compartida por no pocas comedias urbanas y de capa y espada, revela hasta qué punto era éste un tema de preocupación social en la época. De hecho, y como se ha planteado en la primera parte de este artículo, las transformaciones acaecidas en la sociedad urbana del XVI trajeron consigo la extendida percepción social de que no pocos de los valores tradicionales, las identidades y las obligaciones que sostenían la sociedad tradicional, habían entrado en crisis: entre ellas, las figuras de la masculinidad y la feminidad. Maravall ha visto en las tramas del teatro barroco un intento de neutralizar el potencial liberador de esa crisis y reconducirla hacia una glorificación del orden tradicional. Sin negar esa interpretación, quizás demasiado estrecha, desde nuestro punto de vista interesa más centrarla en el funcionamiento de la cultura masiva: la comedia, en ese sentido, absorbe esa creciente preocupación social, explora el conflicto, lo procesa narrativamente y trata de resolver la tensión por él generada, ofreciendo una salida final conservadora que, además de mantener el orden, contribuya a hacer inteligible socialmente un proceso de transformación cultural de mucha mayor complejidad.

\section{Del amor trasgresor al orden matrimonial}

Veámoslo con detenimiento. Durante toda la comedia esa representación de las identidades de género como un espacio maleable y adaptable a la ocasión colisiona con la codificación social de los roles de género $\mathrm{y}$, especialmente, con su adecuación a la naturaleza estamental de la sociedad: una dama de alto linaje, como Leonarda, debe ajustarse a los patrones de conducta propias de su género y de su posición social: el 'yo soy quien soy' típico del drama barroco cifra esa obligatoria adecuación. Ante esa discordancia la comedia opta por dos estrategias simultáneas: por una parte, el enredo sirve para disociar la realidad del personaje de Leonarda espacio de turbulencias, deseos y mentiras- de su apariencia pública-adecuada a su reputación de señora respetable-, y para crear comicidad de su confrontación; por otra parte, la propia estructura de la trama irá reconduciendo algunas de las trasgresiones de la norma hacia un espacio más tranquilizador, en el que su potencial carácter desestructurador se matice considerablemente hasta hacerlas caer del lado del orden social.

De hecho, el recorrido realizado por Leonarda es revelador de las contradicciones de la cuestión del género en la comedia barroca. Si en un primer momento asienta su programa vital en esa idea de convertirse en 'varonil mujer', afirmando su independencia, el control de sus deseos y la posibilidad de vivir sin sometimiento a nadie, pronto la contemplación del galán Camilo le hará caer en el 
enamoramiento - de un modo neoplatónico, a través de la vista-. Al hablar del galán con Julia, su criada, Leonarda riza el rizo, y reflexiona sobre la masculinidad de Camilo, pues su belleza física parece negar la valentía necesaria para ir a su encuentro a oscuras. A ello Julia, voz del sentido común, responde con una exaltación de la virilidad del mancebo ("no como otros mujeriles"), atribuyéndole las características tradicionales de la audacia, el valor y la osadía.

$\begin{array}{ll}\text { LEONARDA: } & \text { ¡Ay, mira que en ser hermoso } \\ & \text { Algo tendrá de mujer! } \\ & \text { Cuanto más que ¿qué Roldán } \\ & \text { Sufriera cubrirse así, } \\ & \text { Y ascuras venir aquí? } \\ & \text { ¡Un mozo hidalgo y galán, } \\ & \text { Un mancebo varonil, } \\ & \text { No como otros mujeriles, } \\ & \text { Con quien fuera el mismo Aquiles } \\ & \text { Ahora cobarde y vil! } \\ & \text { Leandro, ¿no pasó el mar } \\ & \text { Dos mil veces animoso? (vv.1233-1239) }\end{array}$

Esa recurrente tematización de la maleabilidad de las identidades de género se concreta en la comedia barroca en un aspecto fundamental: las mujeres, decididas y apasionadas, constituyen en muchos casos el verdadero motor de la trama, urdiendo tramas para satisfacer unos deseos ocultos que, de hacerse públicos, acabarían con su honor. Por ello, el engranaje de la comedia barroca ataca frontalmente la concepción de la mujer como ser subordinado, sumiso y obediente que presentaban los manuales de conducta femenina, los discursos religiosos y de la buena ecuación. Por el contrario, en La viuda valenciana como en otras comedias barrocas, la mujer protagonista aparece como un sujeto de deseo capaz de movilizar y transformar la realidad para satisfacer sus deseos. En esa representación de la mujer activa articula atributos tradicionalmente asociados a la feminidad con otros codificados socialmente como masculinos.

¿QEONÁ habrá que una mujer determinada
No intente por su gusto? ¿Qué tormento
La mudara del firme pensamiento,
Qué fuego, qué cordel, qué aguda espada?
¿Qué gigante con furia más airada
Intentará subir al firmamento,
O qué Alcides con más atrevimiento
Al centro bajará con alma osada?
Efectos son de un niño poderoso
Haber mi hielo con su amor vencido,
Y aquella de mi primero esposo.


Yo he sido como un río detenido,

Que va, suelta la presa, más furioso;

Y es lo más cierto que mujer he sido. (vv. 803-816).

La actitud deseante de Leonarda es la que, como ya se ha planteado, moverá todos los hilos de la trama, urdiendo engaños, mentiras y ocultamientos a través de los cuales podrá satisfacer sus pasiones y, a la vez, mantener su honra intacta. En un momento dado, llega a ofrecer a Camilo dinero a cambio de compañía, en una insólita propuesta de prostitución masculina. Se trata, a todas luces, de un comportamiento abiertamente trasgresor del orden establecido, que podría ser tachado de inmoral por los conservadores de la época -y que efectivamente lo fue-, que se anuda al omnipresente erotismo de la que impregna toda la trama. Ignacio Arellano, en su estudio sobre la comedia urbana, ha reflexionado sobre la abundancia de personajes, galanes y damas, de un decidido carácter antiheroico, cuya acción está movida únicamente por las bajas pasiones (1995, 43-45), llegando a afirmar que "casi todos los personajes de estas comedias, en suma, participan en medida variable de la ausencia de códigos morales" (Arellano, 1995, 47).

De hecho, muchas de las comedias urbanas articulan en una trama coherente todo un catálogo de situaciones y acciones que transgreden las normas sociales, las subvierten y hacen gala de una supina indiferencia ante las buenas costumbres y valores como la honestidad y la sinceridad. En buena medida, las comedias barrocas ponen en escena, por una parte, los deseos de buena parte de su público de transgredir las convenciones sociales de la sociedad del XVII; pero por otra ponen también en escena no pocos de los miedos y temores que en ese mismo público provoca la ausencia de una norma clara a la que acogerse. En ese sentido, la comedia barroca explora la doble mirada -fascinada y atemorizada- con la que su público enfrenta la nueva modernidad urbana y la evolución de las costumbres, códigos y usos sociales.

El amor (el deseo sexual) constituye, sin duda, la fuerza que abrocha todos esos miedos, deseos y frustraciones y les da coherencia dramática y densidad narrativa. Un amor que se abre como fuerza pulsional capaz de transgredir todas las convenciones del orden social y que, de ese modo, abre la puerta al catálogo de subversiones, inmoralidades y transgresiones que estalla en la comedia barroca. Y un amor que, en el tramo final de la comedia, se transmuta en voluntad de integración social y, por tanto, en deseo de matrimonio. Lo explicó con mayor detalle Oleza:

En la comedia la única motivación realmente seria es el amor. El amor como ideología que legitima el deseo y que justifica, finalmente, el matrimonio. De hecho la comedia es un artefacto semiótico cuya entrada es el deseo y cuya salida es el matrimonio, verificándose el proceso a través del amor. Como explicaba León Hebreo, el amor nace del deseo, y el deseo de la carencia, pues sólo se 
puede desear lo que no se tiene. Pero una vez satisfecho, el deseo no puede perpetuarse como deseo, de hecho debe disolver su empuje en beneficio del amor, y éste finalmente debe canalizar el suyo en la institución social del matrimonio. Así es como la energía individual, salvaje en origen, se resuelve en orden doméstico (Oleza, 1990: 210).

Se ha debatido sobre si el recurrente final conservador anula o no el componente transgresor de las tramas de la comedia, al reconducir la energía subversiva de los comportamientos hasta entonces mostrados hacia una reintegración al orden moral tradicional. No hay duda de que eso ocurre en la mayoría de las comedias barrocas, pero tampoco de que el tiempo de la representación es largo y de que, a lo largo de ella, los espectadores tenían tiempo de divertirse, sufrir y reírse con todas las dislocaciones morales que ésta presenta.

Si se acepta la idea de que las comedias metaforizan en sus tramas, de un modo implícito, la desorientación social de los nuevos sujetos urbanos y algunos de los asuntos que más les preocupaban -la desfiguración de los códigos tradicionales, la ausencia de puntos autoridades fijas, la emergencia de nuevas identidades...- se puede plantear que ese vaivén entre transgresión y reinserción en el orden constituye una forma de procesar todas esas preocupaciones en una sintaxis teatral coherente que dote de inteligibilidad y comunicabilidad a una serie de elementos que resultan angustiosos para la población precisamente porque carece de marcos de inteligibilidad en los que inscribirlos. El teatro barroco, en su tensión entre fuerza propagandística y cultura para el disfrute masivo, se propone a sí mismo, como un marco adecuado para ello.

Más aún cuando el desenlace matrimonial se liga, como en La viuda valenciana, al mantenimiento del orden estamental de la sociedad. En un momento de la trama, debido a la concatenación de enredos, mentiras y ocultamientos en que se sostiene la trama, los frustrados galanes Lisandro, Valerio y Otón sospechan que Leonarda, que huye de sus requiebros y favores, ha de estar amancebada con su criado Urbán, por lo que conspiran para darle un escarmiento ${ }^{4}$. Pero más que la privación de

\footnotetext{
${ }^{4}$ LISANDRO: $\quad$ Pero ¿sabéis qué he pensado, Y nunca lo dije en duda?

VALERIO: ¿Qué?
} 
Leonarda, lo que les escandaliza es la posibilidad de movilidad social que encierra esa unión ilícita y su antinaturalidad -de acuerdo a los criterios del orden tradicional estamental.

En la mecánica argumental, el ilusorio romance entre Leonarda y Urbán no constituía más que un enredo episódico, de poca relevancia narrativa. Sin embargo, su valor residía en traer a escena la problemática de lo estamental, introduciendo una nueva dislocación que, al igual que en el caso de la referente a los géneros, hallaría también su clausura al final de la obra. En su última escena, que viene a abrochar todos los conflictos abiertos durante la representación y a reconducir todos los desórdenes morales, se da matrimonio no solamente a la pareja protagonista de Leonarda y Camilo (nobles ambos), sino también, en perfecta simetría estamental, a las repentinas parejas formadas por Urbán y Julia y Floro y Celia (criados todos ellos de sus nobles amos). Ante esa estricta distribución estamental de los afectos y los contratos familiares, los pseudogalanes se ven obligados a asentir y a aceptar la justicia de dicha resolución.

VALERIO: Justamente lo procuran:

Él noble, ella gallarda (...)

LISANDRO: Casamiento tan honrado

Vuelve en olvido mi amor (vv. 2949-2958).

LISANDRO: Que tiene esta viuda

Galán en casa encerrado.

Que este no acudir a ver

Ninguna cosa de fuera,

Si en casa no le tuviera, ¿cómo se pudiera hacer?

Mujer sola, libre y rica

Y que tantos ha negado,

A fe que hay algún criado

Que al lado de noche aplica.

Y entre los que tiene, Urbán,

Que es bellacón y discreto,

Tengo sospecha en efeto

Que hace oficio de galán,

Porque no se aparta Della,

$\mathrm{Y}$ anda bien puesto y vestido

Siempre se burla atrevido

Y habla en secreto con ella (vv. 1709-1728). 


\section{Conclusiones}

La distribución estamental de la sociedad, los roles codificados de cada género, la relación entre la honra pública y el deseo privado, las nuevas figuras de la masculinidad y, sobre todo, de la feminidad... todo ello forma parte de las preocupaciones fundamentales de esa nueva población urbana que, sin duda, constituyó el público mayoritario de la comedia barroca, como se ha planteado en la primera parte de este artículo. La viuda valenciana es una obra que, como otras muchas de Lope, procesa todas esas problemáticas integrándolas perfectamente en una trama amorosa a la que aportan actualidad y comicidad.

Por ello se puede decir que su funcionamiento es el propio de la cultura masiva que, aunque incipiente, empieza a despuntar en las ciudades españolas a finales del XVI y principios del XVII. El teatro barroco constituye, sin duda, la práctica que redefinirá la relación entre el tiempo de ocio, el espectáculo y las necesidades del nuevo público urbano en las claves propias de la cultura de masas. No es de extrañar que algunas de sus dinámicas y construcciones de sentido se hayan confundido con la práctica propagandística, pues parecen reconducir todos los conflictos sociales que en ella se enuncian a un forzado orden tradicional. Pero lo importante no es tanto eso como el hecho de que las obras barrocas procesan todos esos conflictos, les dan coherencia narrativa y enmarcan en tramas fácilmente inteligibles una serie de elementos que resultan problemáticos porque, precisamente, carecen de marcos narrativos en los que integrarse.

El funcionamiento dramático de La viuda valenciana ejemplifica a la perfección esa lógica. La equivocidad de los signos urbanos, la maleabilidad de los géneros, la movilidad social, la ausencia de moralidad... son elementos que angustian a las nuevas poblaciones urbanas. El trabajo de la obra de Lope, y de buena parte del teatro barroco, consiste en procesar todos esos nudos conflictivos, metaforizarlos y ponerlos en escena de una forma clara y eficaz, integrándolos en tramas que, a pesar de su complejidad, resulten reconocibles para el espectador y le permitan darles un sentido. Sentido del que la nueva población urbana de finales del XVI y principios del XVII se halla necesitada.

\section{Obras citadas}

ARELLANO, Ignacio: «El modelo temprano de la comedia urbana de Lope de Vega», XVIII Jornadas de Teatro Clásico en Almagro, 1995, pp. 37-59.

BAJTIN, Mijail: La cultura popular en la Edad Media y en el Renacimiento. El contexto de François Rabelais. Madrid, Alianza, 1998.

BERMAN, Marshall: Todo lo sólido se desvanece en el aire: la experiencia de la modernidad. México, s. XXI, 1998.

CONNOR SWETLIKI, Catherine: «Hacia una nueva teoría socio-cultural del teatro barroco», Actas del XII Congreso de la Asociación Internacional de Hispanistas de 1995, Vol. 2, Di: Jules Whicker, Birmingham, 1998, pp. 123-129. 
FERRER VALlS, Teresa: «La viuda valenciana de Lope de Vega o el arte de nadar y guardar la ropa» en Monográfico Doce comedias buscan un tablado (F. B. Pedraza.) Cuadernos de Teatro Clásico, 11 (1999), pp. 15-30.

FERRER VALLS, Teresa: «Introducción biográfica y crítica» a La viuda Valenciana. (Lope de Vega) Madrid, Castalia, 2001.

FERRER VALLS, Teresa: «Las intervenciones de "autor" en los textos dramáticos del Siglo de Oro: una copia de La viuda valenciana», Siglos dorados. Homenaje a Agustin Redondo, t. I, Di: Pierre Civil, Madrid, Castalia, 2004, pp. 463-73.

HAVERBECK, Erwin: «El Arte Nuevo de hacer comedias, una nueva estética teatral», Documentos Lingüisticos y Literarios, 14 (1988), pp. 7-17.

MARAVAll, José Antonio: La cultura del barroco. Análisis de una estructura histórica. Barcelona, Ariel, 1983.

MARAVALL, José Antonio: Teatro y literatura en la sociedad barroca. Barcelona, Crítica, 1990.

OlEZA, Joan: «La comedia: el juego de la ficción y el amor», Edad de Oro X (1990), pp. 203-220.

OlEZA, Joan: «Los géneros en el teatro de Lope de Vega: el rumor de las diferencias» Del horror a la risa. Los géneros dramáticos clásicos. Homenaje a Christan Faliu-Lacourt. Di:I. Arellano, V. García Ruiz y M. Vitse Kassel, Edition Reichenberger, 1994, pp. 235-250.

OLEZA, Joan: «Vencer con arte mi fortuna espero. La evolución del primer Lope al Lope del Arte Nuevo» Peribáñez y el Comendador de Ocaña. (Lope de Vega, ed. Donald McGrady). Madrid, Castalia, 1997, pp. IX-LV.

OLIVA, César: «El espacio escénico en la comedia urbana y la comedia palatina de Lope de Vega», XVIII Jornadas de Teatro Clásico en Almagro, 1995.

Roso DíAZ, José: «El recurso del engaño en la obra del primer Lope de Vega», Hesperia. Anuario de Filología Hispánica II (1999), pp. 117-128.

RozAS, Juan Manuel: Significado y doctrina del Arte Nuevo de Lope de Vega. Biblioteca Virtual Miguel de Cervantes, 2002, edición original 1975. 